\title{
Exosomes derived from retinoblastoma cells enhance tumour deterioration by infiltrating the microenvironment
}

\author{
SHUILIAN CHEN* ${ }^{*}$ XI CHEN*, JIN QIU, PEI CHEN, XIAOKUN HAN, YIHUI WU, JIEJIE ZHUANG, MENG YANG, \\ CHUANGRAN WU, NANDAN WU, YING YANG, JIAN GE, KEMING YU and JING ZHUANG
}

State Key Laboratory of Ophthalmology, Zhongshan Ophthalmic Center, Sun Yat-sen University, Guangzhou, Guangdong 510000, P.R. China

Received July 21, 2020; Accepted October 15, 2020

DOI: $10.3892 /$ or.2020.7858

\begin{abstract}
The survival of young children (under 5 years of age) with malignant retinoblastoma remains poor, and clarification of the mechanism underlying tumour development is urgently needed. The present study aimed to reveal the role of exosomes (EXOs) from retinoblastoma cells in tumour development. The in vitro data indicated that EXOs derived from WERI-Rb1 cells significantly inhibited the antitumour activity of macrophages and induced bone marrow mesenchymal stem cells to promote tumour growth via an increase in monocyte chemotactic protein 1 (also known as C-C motif chemokine ligand 2) levels. In vivo data from a xenotransplantation model also showed that EXOs infiltrated the spleen, which induced a decrease in leukocytes and natural killer (NK) cells. Accordingly, the proportion of tumour-associated macrophages was increased and the proportion of NK cells was decreased in tumours injected with EXOs compared with those injected with the control. EXOs were absorbed by Kupffer cells, and more metastases were observed in the liver. Thus, these results suggested that EXOs derived from retinoblastoma promoted tumour progression by infiltrating the microenvironment. Moreover, microRNAs (miRs), including miR-92a, miR-20a, miR-129a and miR-17, and C-X-C chemokine receptor type 4 and thrombospondin-1 were detectable in EXOs, which might account for EXO-mediated tumour deterioration.
\end{abstract}

\section{Introduction}

Retinoblastoma is the most common intraocular malignant tumour that threatens the health of children, affecting

Correspondence to: Professor Jing Zhuang or Professor Keming Yu, State Key Laboratory of Ophthalmology, Zhongshan Ophthalmic Center, Sun Yat-sen University, 7 Jinsui Road, Tianhe, Guangzhou, Guangdong 510000, P.R. China

E-mail: zhuangj@mail.sysu.edu.cn

E-mail: yukeming@mail.sysu.edu.cn

*Contributed equally

Key words: exosomes, retinoblastoma, macrophages, tumour microenvironment, metastasis
1:15,000-1:20,000 live births (1). Current treatments for retinoblastoma include chemotherapy, plaque radiotherapy, external beam radiotherapy, cryotherapy and surgery (2). However, despite the clinical response to such comprehensive strategies, tumour metastasis and extraocular invasion in the advanced stage still cause death in children $(3,4)$. Therefore, investigation of the underlying mechanism of retinoblastoma tumourigenesis and development is necessary to improve therapeutic efficacy.

A growing body of literature has reported that the microenvironment regulates tumour progression and metastasis $(5,6)$. Macrophages are plastic cells and have multiple bioactivities in response to environmental signals. Interferon and TLR ligands could orient macrophage function toward the M1 phenotype (high levels of proinflammatory), while IL-4 and IL-13 activate the M2 phenotype (tissue remodelling and promotion of tumour progression) (7). The tumour microenvironment can induce macrophages to adopt a tumour-promoting state (7). IL-6, TNF- $\alpha$ and monocyte chemotactic protein-1 (MCP-1) are highly expressed in resident tumour-associated macrophages (TAMs) or in macrophages derived from peripheral reservoirs, such as the bone marrow $(\mathrm{BM})$ and spleen $(8,9)$. TAMs contribute to matrix breakdown and tumour cell motility (10). However, the mechanism of activation of these cells by tumour cells is not well defined.

Exosomes (EXOs) are endocytosis-derived small membrane vesicles $(40-150 \mathrm{~nm})$ that are composed of proteins, lipids, microRNA (miRNA/miR) and mRNA surrounded by a phospholipid bilayer and are secreted into the extracellular space (11). A growing number of studies have demonstrated that EXOs and other extracellular vesicles secreted by tumour cells play an important role in cell-to-cell communication (12-16). EXOs can bind to target cells, fuse with the membrane and transfer their contents to mediate intercellular communication. Additionally, tumour-derived EXOs can facilitate tumour malignancy (17). Moreover, previous reports have verified that tumour-derived EXOs contribute to the establishment of a premetastatic niche and generate oncogenic microenvironments at distant metastatic sites by modulating stromal cells and remodelling the extracellular matrix $(18,19)$.

Nevertheless, very little is known concerning the possible functions of retinoblastoma cell EXOs in tumour progression. Based on the aforementioned evidence, the aim of the present study was to determine the effects of retinoblastoma 
cell EXOs to elucidate the possible underlying mechanisms of retinoblastoma deterioration.

\section{Materials and methods}

Cell culture. WERI-Rb1 human retinoblastoma cells (American Type Culture Collection) were cultured in RPMI-1640 (Gibco; Thermo Fisher Scientific, Inc.) with $10 \%$ foetal bovine serum (FBS; Gibco; Thermo Fisher Scientific, Inc.). Murine macrophages RAW264.7 (The Cell Bank of Type Culture Collection of the Chinese Academy of Sciences) were cultured in DMEM (Gibco; Thermo Fisher Scientific, Inc.) with 10\% FBS. Bone marrow mesenchymal stem cells (BMSCs) were acquired from C57 mice and BMSCs from passages 4-6 were cultured in DMEM with $10 \%$ FBS for use $\left(8 \times 10^{4} / \mathrm{ml}\right)$. These cells were incubated in a humidified atmosphere with a mixture of $1 \% \mathrm{O}_{2}$, $5 \% \mathrm{CO}_{2}$ and $94 \% \mathrm{~N}_{2}$ at $37^{\circ} \mathrm{C}$.

Primary BMSC isolation. BMSCs were isolated from the bone marrow of $\mathrm{C} 57 \mathrm{BL} / 6$ mice using previously described methods (20). Briefly, 4-6 week old C57 BL/6 mice were anesthetized by intraperitoneal injection of Nembutal $(30 \mathrm{mg} / \mathrm{kg}$; cat. no. P3761, Sigma-Aldrich; Merck KGaA) and then sacrificed by cervical dislocation, and their tibias and femurs were separated aseptically. DMEM was used to flush the marrow out with a sterile 25-guage needle and the extruded BM cells were filtered through a $70-\mu \mathrm{m}$ cell strainer (BD Biosciences) and centrifuged at $1,000 \mathrm{xg}$ for $5 \mathrm{~min}$ at $37^{\circ} \mathrm{C}$. The BM cells were resuspended with DMEM containing 10\% FBS and plated into flasks. The cells were treated with $0.25 \%$ trypsin $/ 1 \mathrm{mM}$ EDTA for 2 min until the cells reached $90 \%$ confluence. The culture medium was changed every 3 days. After 3-4 passages, isolated cells were used for experiments.

EXO isolation, characterization and treatment. EXOs were purified from WERI-Rb1-derived conditioned medium (collected from $48 \mathrm{~h}$ cell cultures with RPMI-1640 and $10 \%$ exosome-free FBS) by ultracentrifugation, as outlined previously (21). The FBS was depleted of EXOs through ultracentrifugation at $110,000 \times \mathrm{g}$ overnight at $4^{\circ} \mathrm{C}$. After $48 \mathrm{~h}$, the conditioned media were centrifuged at $1,000 \mathrm{x}$ g for $5 \mathrm{~min}$, followed by $10,000 \mathrm{x}$ g for $30 \mathrm{~min}$, and then ultracentrifugation of the supernatants was performed at $100,000 \times \mathrm{g}$ for 90 min. All centrifugation was performed at $4^{\circ} \mathrm{C}$. The EXOs were washed with phosphate-buffered saline (PBS), and then ultracentrifugation was carried out at $100,000 \mathrm{x}$ for $90 \mathrm{~min}$ at $4^{\circ} \mathrm{C}$, following which, EXOs were resuspended in PBS. The size and number of EXOs were counted by Nano-Flow cytometry, according to a previous method (22), which is the imaging of individual fluorescently labelled EXOs passing through nanochannels in a pressure-driven flow (23). Lastly, the protein concentration was measured using a Bicinchoninic Acid Protein Assay Kit (Beyotime Institute of Biotechnology).

EXOs were viewed by transmission electron microscopy (FEI Tecnai Spirit G2; Thermo Fisher Scientific, Inc.), according to a previous method (21). Briefly, freshly isolated EXO pellets were transferred to a copper grid coated with carbon in a 30- $\mu$ l drop of $1 \%$ glutaraldehyde for $5 \mathrm{~min}$ and then the grid was washed with distilled water. The grids were stained with $4 \%$ uranyl-acetate solution for $10 \mathrm{~min}$ at $37^{\circ} \mathrm{C}$, and then treated with a 50- $\mu 1$ drop of methyl cellulose for 5 min on ice. Then, the grid was washed with distilled water and observed under transmission electron microscopy at $80 \mathrm{Kv}$.

For EXO labelling, EXOs were fluorescently labelled using the PKH26 membrane dye (Sigma-Aldrich; Merck KGaA), according to a previous method (24). Briefly, EXOs were resuspended into $1 \mathrm{ml}$ Diluent $\mathrm{C}$ and $6 \mu 1 \mathrm{PKH} 26$ dye was added for $5 \mathrm{~min}$ at room temperature. Then, the reaction was quenched by adding $2 \mathrm{ml} \mathrm{10 \%} \mathrm{BSA} \mathrm{(cat.} \mathrm{no.} \mathrm{0332;} \mathrm{Amresco,} \mathrm{LLC)}$ followed by ultracentrifugation at $100,000 \mathrm{x}$ f for $2 \mathrm{~h}$ to remove excess dye.

BMSCs and WERI-Rbl co-culture. For the co-culture experiments, BMSCs $\left(4 \times 10^{4}\right)$ treated with PBS or EXOs were plated in 24-well plates. WERI-Rb1 cells $\left(4 \times 10^{4}\right)$ were suspended in EXO-free medium and seeded into Transwell chambers with $0.4-\mu \mathrm{m}$ pore size inserts (BD Biosciences). The viability of BMSCs and WERI-Rb1 cells were assessed using a CCK-8 assay after $24 \mathrm{~h}$. BMSC RNA was extracted for RT-qPCR analysis.

Cell viability assay. The viabilities of WERI-Rb1 cells and RAW264.7 macrophages treated with EXOs or PBS were detected using a Cell Counting Kit-8 (CCK-8) assay (Dojindo Molecular Technologies, Inc.). Each group of cells was incubated with CCK- 8 reagent for $3 \mathrm{~h}$ at $37^{\circ} \mathrm{C}$. Finally, the absorbance was assessed at $450 \mathrm{~nm}$ and recorded.

Reverse transcription-quantitative $(R T-q) P C R$ analysis. Total RNA from WERI-Rb1 cells, RAW264.7 cells and BMSCs was extracted with TRIzol $^{\circledR}$ reagent (Invitrogen; Thermo Fisher Scientific, Inc.). Total RNA ( $1 \mu \mathrm{g})$ was subjected to reverse transcription using a PrimeScript ${ }^{\mathrm{TM}}$ RT Reagent kit (Takara Biotechnology Co., Ltd.), following the manufacturer's protocol. Total RNA from exosomes was extracted with TRIzol ${ }^{\circledR}$ reagent (Invitrogen; Thermo Fisher Scientific, Inc.) and Dr GenTLE ${ }^{\mathrm{TM}}$ Precipitation Carrier (Takara Biotechnology Co., Ltd.). Total RNA (1 $\mu \mathrm{g})$ was subjected to reverse transcription using a Mir- $\mathrm{X}^{\mathrm{TM}}$ miRNA First-Strand Synthesis Kit (Takara Biotechnology Co., Ltd.), following the manufacturer's protocol. RT-qPCR was performed with a SYBR Prime Script RT-PCR Kit on a Roche 480 system (Roche Diagnostics) following the manufacturer's protocols. PCR conditions were as follows: $94^{\circ} \mathrm{C}$ for $5 \mathrm{~min}$, followed by 40 cycles of $94^{\circ} \mathrm{C}$ for $30 \mathrm{sec}, 62^{\circ} \mathrm{C}$ for $30 \mathrm{sec}$, and $72^{\circ} \mathrm{C}$ for $30 \mathrm{sec}$. The relative target gene expression was quantitated using the $2^{-\triangle \Delta \mathrm{Cq}}$ method (25) and normalized to the endogenous expression of b-actin, GAPDH or miR-16. The primers for mRNA and miRNA detection are listed in Tables SI and SII, respectively.

Immunofluorescence assay. Cells or tissue sections (tumour, spleen and liver) were fixed with $4 \%$ paraformaldehyde $\left(10 \mathrm{~min}\right.$ at $\left.37^{\circ} \mathrm{C}\right)$, and then blocked with $1 \%$ BSA and $0.2 \%$ Triton X-100 for $30 \mathrm{~min}$ at $37^{\circ} \mathrm{C}$. Samples were incubated with primary antibodies overnight at $4^{\circ} \mathrm{C}$, including anti-CD $49 \mathrm{~b}$ for natural killer (NK) cells (1:100; cat. no. 14-5971-85; Invitrogen; Thermo Fisher Scientific, Inc.), anti-CD45 for leukocytes (1:100; cat. no. sc-1178; Santa Cruz Biotechnology, Inc.), 
anti-CD68 for macrophages (1:100; cat. no. BA3638; Wuhan Boster Biological Technology Co., Ltd.), anti-Ki-67 for proliferative cells (1:500; cat. no. MA5-14520; Thermo Fisher Scientific, Inc.), anti-Vimentin for invasive tumour cells (1:100; cat. no. sc-6260; Santa Cruz Biotechnology, Inc.). After washing with PBS, samples were stained with the appropriate Alexa Fluor-conjugated secondary antibody for $1 \mathrm{~h}$ at $37^{\circ} \mathrm{C}$ (Alexa Fluor 555 anti-rabbit lgG, 1:500, cat. no. 4413; Alexa Fluor 488 anti-rabbit $\lg \mathrm{G}, 1: 500$, cat. no. 4412; Alexa Fluor 488 anti-mouse $\lg \mathrm{G}, 1: 500$, cat. no. 4408; all purchased from Cell Signaling Technology, Inc.). Images were captured using fluorescence microscopy (Axio Imager Z1; Carl Zeiss AG; magnification, $\mathrm{x} 100$ ).

Immunofluorescence staining for cells was quantified by analysing the fraction or number of positively-stained pixels per total field using ImageJ software (version 1.51; National Institutes of Health). This protocol was used in a previous study (26). Briefly, the images were binarized to black and white with a common threshold level such that white pixels represented positive cells and were quantified by histogram analysis using GraphPad Prism system 7 (GraphPad Software, Inc.). At least five random sections per mouse were used for quantification.

Western blotting. Whole proteins of cells and EXOs were extracted using a RIPA lysate kit (Beyotime Institute of Biotechnology). The protein concentration was determined with a BCA assay (Beyotime Institute of Biotechnology). Total protein $(30 \mu \mathrm{g})$ from each sample was separated via $10 \%$ sodium dodecyl sulfate-polyacrylamide gel by electrophoresis, and subsequently transferred to a polyvinylidene difluoride membrane. The membranes were blocked with $5 \%$ BSA for $2 \mathrm{~h}$ at $37^{\circ} \mathrm{C}$, then incubated with primary antibodies overnight at $4^{\circ} \mathrm{C}$. The following primary antibodies were used: Anti-GAPDH (1:10,000; cat. no. 10494-1-AP; ProteinTech Group, Inc.), anti-Tubulin (1:1,000; cat. no. sc-5274; Santa Cruz Biotechnology, Inc.), anti-CD63 (1:1,000; cat. no. EXOAB-CD63A-1; Systems Biosciences, LLC), anti-tumour susceptibility gene 101 protein $(1: 1,000$; cat. no. ab125011; Abcam), anti-CD9 (1:1,000; cat. no. 13403; Cell Signalling Technology, Inc.), anti-heat shock $70 \mathrm{kDa}$ protein 1A (1:1,000; cat. no. 4873; Cell Signalling Technology, Inc.), anti-proliferating cell nuclear antigen (PCNA; 1:1,000; cat. no. 13110; Cell Signalling Technology, Inc.), anti-Bax (1:1,000; cat. no. 2772; Cell Signalling Technology, Inc.), anti-Bcl-2 (1:1,000; cat.no. A00040-1; Wuhan Boster Biological Technology, Ltd.), anti-Caspase-3 (1:1,000; cat. no. 9662; Cell Signalling Technology, Inc.), anti-C-X-C chemokine receptor type 4 (CXCR4; 1:1,000; cat. no. ab124824; Abcam), anti-MMP2 (1:1,000; cat. no. 10373-2-AP; ProteinTech Group, Inc.) and anti-thrombospondin-1 (TSP-1; 1:1,000; cat. no. ab1823; Abcam). Membranes were then incubated with HRP-conjugated anti-mouse IgG (1:3,000; cat. no. 7076s; Cell Signalling Technology, Inc.) or anti-rabbit IgG (1:10,000; cat. no. 7074s; Cell Signalling Technology, Inc.) for $1 \mathrm{~h}$ at $37^{\circ} \mathrm{C}$, following which the blots were visualized with an enhanced chemiluminescence system (Thermo Fisher Scientific, Inc.). GAPDH or Tubulin were used as loading controls. The band intensity was semi-quantified by ImageJ software (version 1.51; National Institutes of Health).
Murine xenograft model of retinoblastoma. A total of 20 female athymic nude mice (4-6 weeks old) were subcutaneously injected in the left submaxillary region with $300 \mu \mathrm{l}$ WERI-Rb1 cells $\left(1 \times 10^{7}\right)$ mixed with Matrigel $(18 \mathrm{mg} / \mathrm{ml}$, vol/vol, 1:1). One week after subcutaneous WERI-Rb1 cell injection, successfully transplanted mice (tumour volume, $\left.>200 \mathrm{~mm}^{3}\right)$ were randomly divided into two groups $(\mathrm{n}=10)$ and subcutaneously injected with an equal volume of PBS or EXOs $(75 \mu \mathrm{g})$ into the site of primary tumours every 3 days for 15 days. The tumour sizes of the mice were measured and the tumour volume was calculated as the length $\mathrm{x}$ width ${ }^{2} / 2$ every 5 days. Mice were anesthetized by intraperitoneal injection of Nembutal $(30 \mathrm{mg} / \mathrm{kg})$ and then sacrificed by cervical dislocation 15 days after PBS or EXO injection. Tumours, spleens and livers were harvested and stored at $-80^{\circ} \mathrm{C}$. Sham surgery that did not include the injection of tumour cells, PBS and EXOs was performed on three female athymic nude mice (4-6 weeks old).

Ethics statement. A total of 23 female nude mice (age, 4-6 weeks; weight, 16-18 g) and four C57 BL/6 mice (age, 4-6 weeks; weight, 16-20 g) were obtained from the Ophthalmic Animal Laboratory, Zhongshan Ophthalmic Center, Sun Yat-sen University (Guangzhou, China). All animal experiments adhered to the ARVO Statement for the Use of Animals in Ophthalmic and Vision Research (27) and were approved and monitored by the Institutional Animal Care and Use Committee of Zhongshan Ophthalmic Center [approval no. SYXK (YUE) 2018-101, 2018-168, 2019-009]. The mice had free access to food and water and were maintained under a 12-h light/dark cycle in an air-conditioned room $\left(16-26^{\circ} \mathrm{C}\right.$ and $\left.40-70 \%\right)$.

Statistical analysis. Data are presented as the mean \pm standard deviation, and the differences between mean values were evaluated using a Student's two-tailed t-test (for two groups) or analysis of variance followed by Tukey's post hoc (for multiple group comparisons). $\mathrm{P}<0.05$ was considered to indicate a statistically significant difference.

\section{Results}

EXOs derived from WERI-Rb1 cells increases cell viability. WERI-Rb1 cells grew in loose grape-like clusters and were cultured in EXO-free media (Fig. 1A). EXOs were isolated from cells, as described in the materials and methods section, and observed under a transmission electron microscopy. The diameter of vesicles was $\sim 30-100 \mathrm{~nm}$ (Fig. 1B). The NanoFCM tracking analysis also indicated that the size distribution and number of exosomes derived from WERI-Rb1 cells, ranged from 50 to $150 \mathrm{~nm}$ with a mean size of $\sim 77 \mathrm{~nm}$ (Fig. 1C). Additionally, known exosome putative markers, including HSP70, TSG101, CD9 and CD63, were identified by western blotting (Fig. 1D). To determine whether EXOs could affect the growth of retinoblastoma cells, WERI-Rb1 cells were incubated with EXOs labelled with PKH26 (red). As presented in Fig. 1E, EXOs were taken up by WERI-Rb1 cells at $24 \mathrm{~h}$ after incubation. The CCK- 8 assay indicated that the viability of WERI-Rb1 cells treated with EXOs derived from the same cells was significantly increased compared with that of 
A
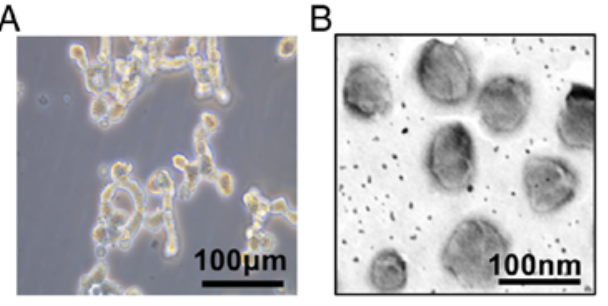

C

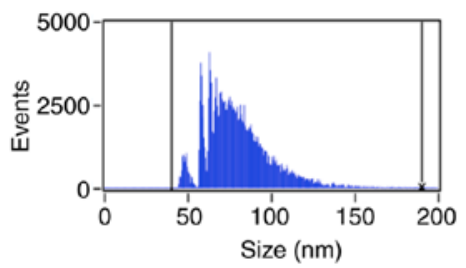

D
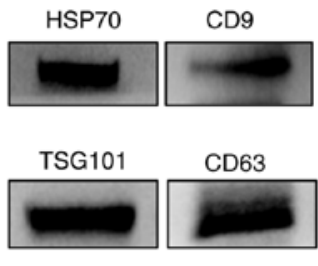

E

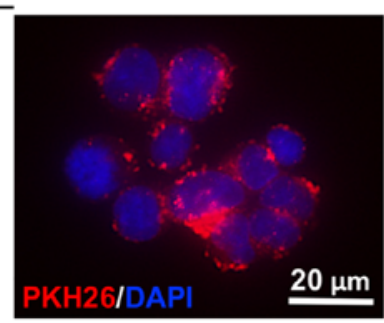

F

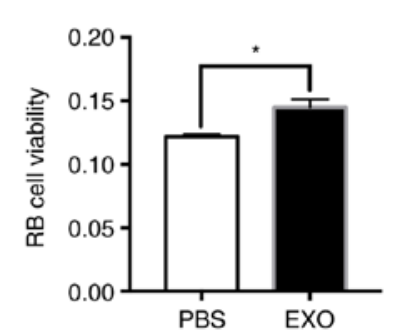

G

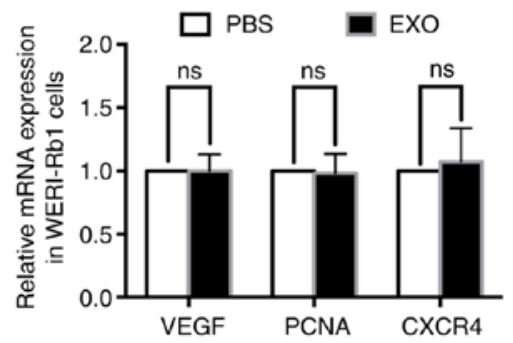

Figure 1.EXOs derived from WERI-Rb1 cells slightly increase cell viability. (A) Loose grape-like clusters of WERI-Rb1 cells. Scale bar, $100 \mu \mathrm{m}$. (B) Representative transmission electron microscopy images of WERI-Rb1 EXOs. The diameter of vesicles was between 30 and $100 \mathrm{~nm}$. Scale bar, $100 \mathrm{~nm}$. (C) Nano-Flow cytometry tracking analysis indicated that the size distribution and number of EXOs derived from WERI-Rb1 cells ranged from 50 to $150 \mathrm{~nm}$ with a mean size of $\sim 77 \mathrm{~nm}$. (D) Western blot analysis of different protein markers (HSP70, CD9, TSG101 and CD63) of EXOs collected from WERI-Rb1 cells. (E) EXOs labelled with PKH26 were engulfed by WERI-Rb1 cells. Scale bar, $20 \mu \mathrm{m}$. (F) PBS or EXOs were added to WERI-Rb1 cells, and WERI-Rb1 cell viability was measured using a Cell Counting Kit-8 assay (red, PKH26; blue, DAPI). (G) Reverse transcription-quantitative PCR showed that there was no significant difference between the mRNA levels of VEGF, PCNA and CXCR4 in the PBS and EXO groups. Data are from three independent experiments. *P<0.05. EXO, exosome; ns, no significance; HSP70, heat shock $70 \mathrm{kDa}$ protein 1A; PCNA, proliferating cell nuclear antigen; CXCR4, C-X-C chemokine receptor type 4; RB, retinoblastoma.

the control (PBS, 0.122 $\pm 0.002 ; \mathrm{EXO}, 0.145 \pm 0.005 ;{ }^{*} \mathrm{P}<0.05$ Fig. 1F). However, the mRNA expression levels of VEGF, PCNA and CXCR4, which can be used to predict cancer cell malignancy (28-30), were not affected by EXOs [no significance (ns); Fig. 1G]. These data suggested that EXOs derived from WERI-Rb1 cells have no significant influence on malignancy in vitro.

EXOs derived from WERI-Rbl cells affect the antitumour activity of macrophages and BMSCs in vitro. To reveal the effect of EXOs on immune cells, RAW264.7 cells, which are well-characterized with regard to their macrophage-specific immune functions (31), were incubated with EXOs from WERI-Rb1 cells labelled with PKH26 (red). At $6 \mathrm{~h}$ after incubation, EXOs could be taken up by RAW264.7 cells. PKH26 was partially colocalized with CD68 (green, a specific marker of macrophages; Fig. 2A). Moreover, the cells changed from round to spindle-shaped with ramified morphology (Fig. 2B), which indicated that macrophages were activated. However, EXOs significantly increased the levels of IL-6 and MCP-1 (relative

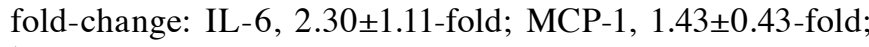
$\left.{ }^{*} \mathrm{P}<0.05\right)$. The increase in IL-6 and MCP-1 expression implied that the antitumour activity of macrophages was inhibited by EXOs, which was consistent with a previous study (6). There was no significant difference in TNF- $\alpha$ expression between the PBS and EXO groups (relative fold-change: 1.16 \pm 0.28 -fold; ns; Fig. 2C). It has been speculated that TNF- $\alpha$ expression does not change in the early response of RAW 264.7 cells to EXOs (24 h). Accordingly, treatment with EXOs also resulted in decreased proliferation of RAW264.7 cells (PBS, 0.949 \pm 0.271 ; EXO, 0.303 $\pm 0.124 ;{ }^{*} \mathrm{P}<0.05$; Fig. 2D).

To assess the effect of EXOs on the bioactivity of BMSCs and WERI-Rb1 cells, a co-culture system was used to mimic retinoblastoma physiological conditions. The primary BMSCs were incubated with PBS or EXOs and co-cultured with WERI-Rb1 cells for $24 \mathrm{~h}$ (Fig. 2E). As shown in Fig. 2F, EXOs could significantly increase the expression levels of IL-6 and MCP-1 in BMSCs (relative fold-change: IL-6, 7.54 \pm 1.50 -fold; MCP-1, 7.62 \pm 1.39 -fold; * $\mathrm{P}<0.05$ ), which could promote tumour growth and metastasis $(32,33)$. Similarly, there was no significant difference in TNF- $\alpha$ expression between the PBS and EXO groups in BMSCs (relative fold-change: 0.66 \pm 0.26 -fold; ns). Moreover, the viability of WERI-Rb1 cells was significantly increased (PBS, 0.14 \pm 0.03 ; EXO, 0.21 $\pm 0.02 ;{ }^{*} \mathrm{P}<0.05$ ) in the co-culture system, whereas the viability of BMSCs was not affected by EXOs (PBS, 0.42 \pm 0.05 ; EXO, 0.46 \pm 0.02 ; ns) (Fig. 2G).

Taken together, these findings demonstrated that EXOs derived from WERI-Rb1 cells could inhibit the antitumour activity of macrophages and induce the BMSCs to promote retinoblastoma cell growth in vitro.

EXOs derived from WERI-Rbl cells increase retinoblastoma growth. To confirm the in vitro results, a xenotransplantation model was established and then mice were regularly injected with EXOs or PBS around the tumour. EXOs in tumour tissues were observed after 2 days and were markedly increased in the loose tumour tissue at day 10. It was observed that EXOs were mainly located in loose tissue outside the tumour, and few were detected in the dense tissue within the tumour (Fig. 3A). However, quantification of tumour volume growth showed that EXO treatment significantly increased retinoblastoma tumour volume 10 days after transplantation (PBS, 66 $\pm 172 \mathrm{~mm}^{3}$; EXO, $259 \pm 224 \mathrm{~mm}^{3}$; $\mathrm{P}<0.05$; Fig. 3B and C). Moreover, the protein levels of PCNA were significantly elevated by EXOs in the tumour (PBS, 0.77 \pm 0.18 ; EXO, 1.08 \pm 0.31 ; ${ }^{*} \mathrm{P}<0.05$; Fig. 3D). Furthermore, the protein levels of apoptosis-related Bcl-2, Bax 
A

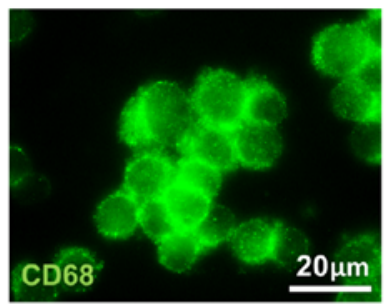

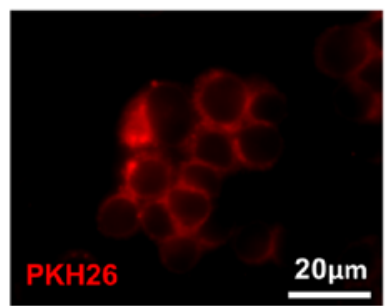

C

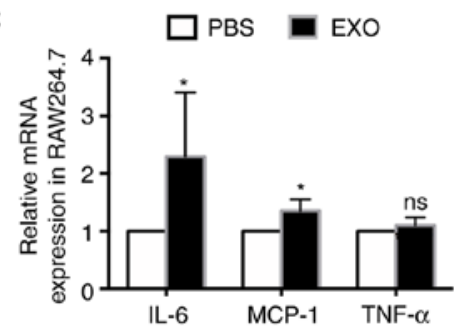

F

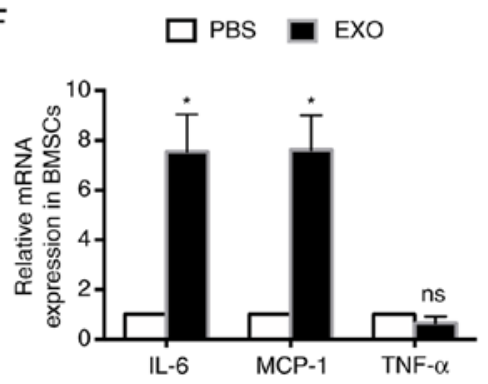

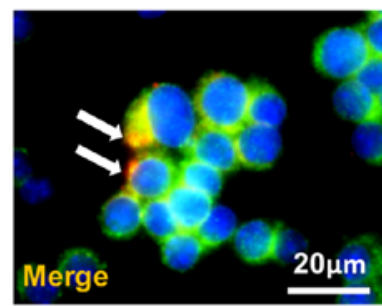

D

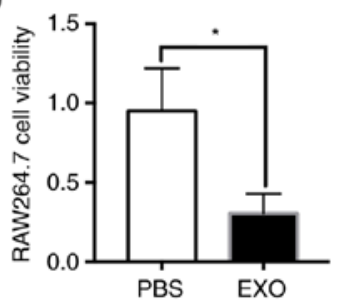

G

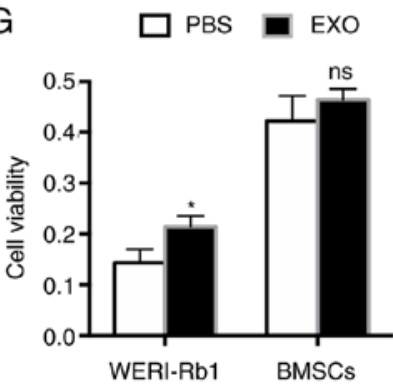

Figure 2. EXOs derived from WERI-Rb1 cells affect the antitumour activity of macrophages and BMSCs in vitro. (A) EXOs labelled with PKH26 were engulfed by RAW264.7 cells. (green, CD68; red, PKH26). Scale bar, $20 \mu \mathrm{m}$. (B) Morphology changes of RAW264.7 cells following treatment with EXOs. Scale bar, $50 \mu \mathrm{m}$. (C) RT-qPCR analysis of IL-6, MCP-1 and TNF- $\alpha$ expression in RAW264.7 cells incubated with EXOs derived from WERI-Rb1 cells for 24 h. (D) Cell Counting Kit-8 assay showed that RAW264.7 cell viability was significantly decreased by EXOs. (E) WERI-Rb1 cells and BMSCs co-culture system, BMSCs treated with PBS or EXOs were co-cultured with WERI-Rb1 cells for 24 h. (F) RT-qPCR analysis of IL-6, MCP-1 and TNF- $\alpha$ expression in BMSCs from the co-culture system. (G) Cell viability of WERI-Rb1 cells and BMSCs from the co-culture system. Data are from three independent experiments. * P<0.05 vs. PBS group. EXO, exosome; ns, no significance; RT-qPCR, reverse transcription-quantitative PCR; BMSC, bone marrow mesenchymal stem cells; MCP-1, monocyte chemotactic protein-1; RB, retinoblastoma.

and caspase-3 were detected. As presented in Fig. 3E, the ratio of Bcl-2 to Bax was significantly increased (PBS, 0.58 \pm 0.23 ; EXO, 1.44 $\left.\pm 0.87 ;{ }^{*} \mathrm{P}<0.05\right)$, whereas the relative expression of cleaved caspase-3 was decreased (PBS, 0.28 \pm 0.18 ; EXO, $\left.0.17 \pm 0.14 ;{ }^{*} \mathrm{P}<0.05\right)$ in the EXO group. In summary, EXOs derived from WERI-Rb1 cells could inhibit tumour apoptosis and promote tumour growth in vivo.

EXOs derived from WERI-Rbl cells could promote the malignancy of retinoblastoma. Ki-67 is widely used to measure tumour proliferation and assess the prognosis of patients with cancer (34). Vimentin, an intermediate filament protein, is often used as a marker of invasive tumour cells due to its expression during activation of the epithelial-mesenchymal transition (35). Therefore, tissue sections were double stained with antibodies against Ki-67 and Vimentin. As shown in Fig. 4A and B, the relative Vimentin-positive area (PBS, $11.35 \pm 2.43 \%$; EXO, 21.04 $\pm 3.58 \%$; ${ }^{*} \mathrm{P}<0.05$ ) and $\mathrm{Ki}-67$-positive rate in cells were significantly increased

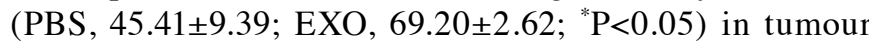
tissues injected with EXOs. Moreover, the protein levels of CXCR4 and MMP2, which play a crucial role in malignancy and metastasis during tumour progression $(36,37)$, were significantly increased (CXCR4: PBS, 0.225 \pm 0.088 ; EXO,

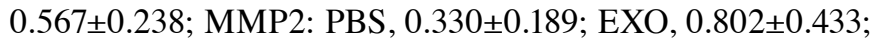
${ }^{*} \mathrm{P}<0.05$; Fig. $4 \mathrm{C}$ and D).

Furthermore, TAMs, a significant subset of tumour-infiltrating immune cells, play an important role in tumour growth and metastasis $(38,39)$. Therefore, TAMs were evaluated in whole tumour sections using staining with an anti-CD68 antibody (Fig. 4E). Accordingly, the CD68-positive area was significantly increased in tumour tissues treated with EXOs compared with that in control tissue (PBS, 1.18 $\pm 0.41 \%$;

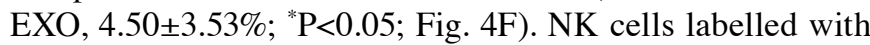
$\mathrm{CD} 49 \mathrm{~b}$ (red) surrounded tumour cells and were decreased in the EXO-treated group (PBS, 14.94 \pm 3.77 ; EXO, 3.66 \pm 2.29 ; ${ }^{* * *} \mathrm{P}<0.001$; Fig. 4G and $\mathrm{H}$ ). Therefore, these results also partially supported the aforementioned results that demonstrated that exosomes derived from WERI-Rb1 cells promoted tumour growth and malignancy.

EXOs derived from WERI-Rbl cells inhibit innate immunity in vivo. Although athymic nude mice with immunodeficiency were used in the present study, the mice still exhibited intact 
A

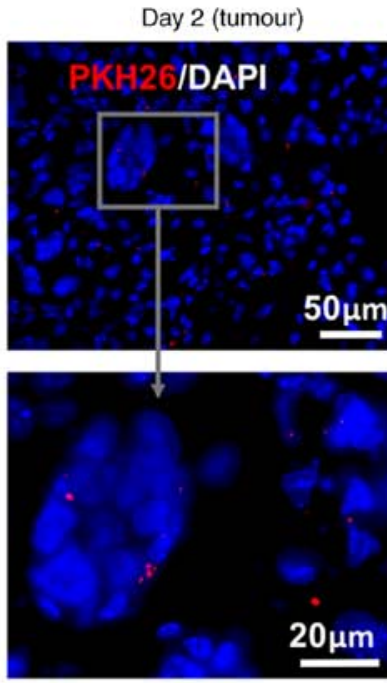

Day 10 (tumour)

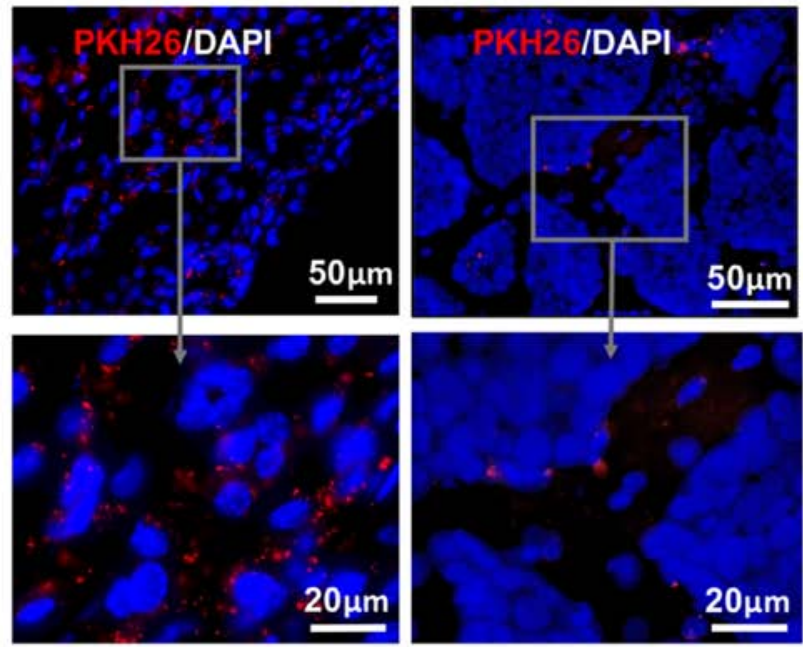

C

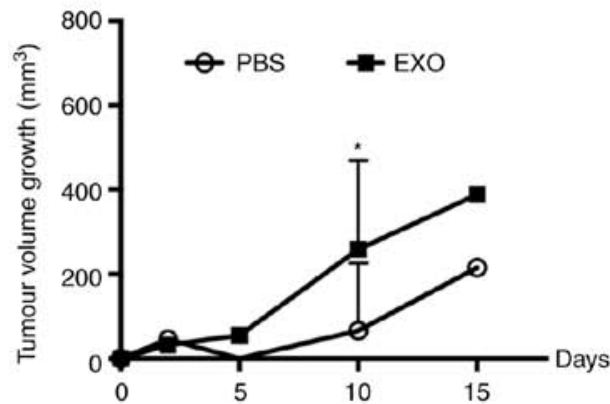

D
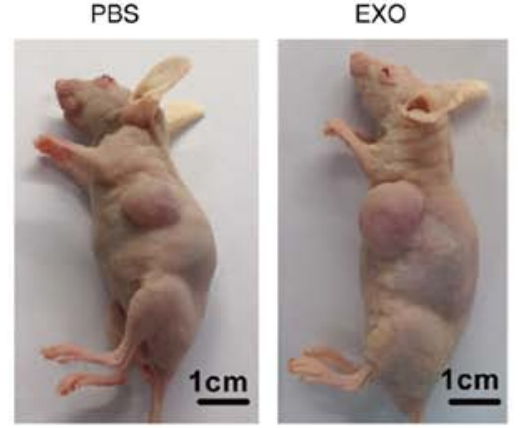

E
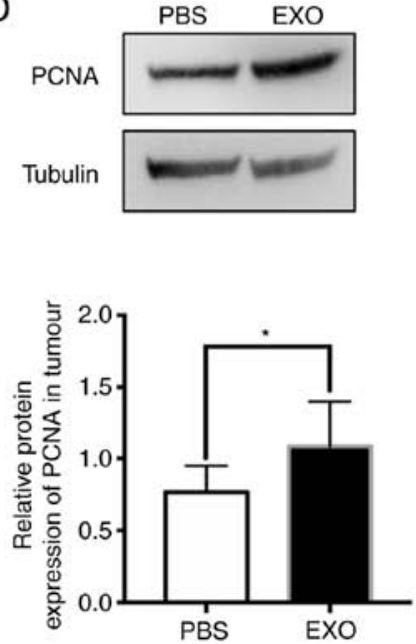
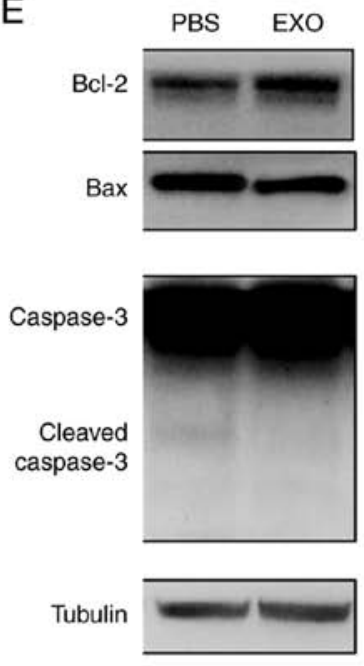
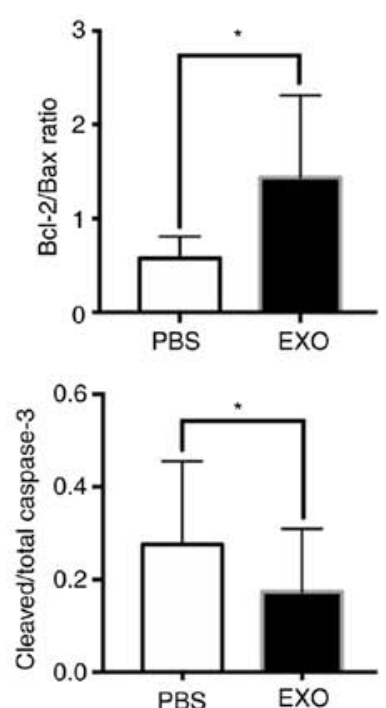

Figure 3. EXOs derived from WERI-Rb1 cells were engulfed by tumour cells and promoted the growth of retinoblastoma. (A) PKH26-labelled EXOs (red) were internalized by cells from tumour tissues 2 or 10 days following EXO injection. DAPI was used to stain nuclei. Scale bar, 50 or $20 \mu \mathrm{m}$. (B) Representative macroscopic appearance of the xenotransplantation model 15 days after injection of WERI-Rb1 cells. Tumours were larger in EXO-injected mice than in PBS-injected mice. Scale bar, $1 \mathrm{~cm}$. (C) Tumour volume changes in the xenotransplantation model. Tumour volume significantly increased in the EXO-injected group compared with the PBS-injected group 10 days following injection, whereas there was no significance at day 15 after treatment $(\mathrm{n}=10)$. (D) Representative western blot images of PCNA protein and semi-quantitative data showed that PCNA expression in tumours was increased by EXOs (n=7). (E) Representative western blot image of Bcl-2, Bax, total Caspase- 3 and cleaved Caspase- 3 protein and semi-quantitative data showed that the Bcl-2 to Bax ratio in tumours was increased by EXOs and that the cleaved Caspase- 3 to total Caspase- 3 ratio was decreased by EXOs ( $n=8)$. " $\mathrm{P}<0.05$ vs. PBS group. EXO, exosome; PCNA, proliferating cell nuclear antigen.

innate and adaptive immunity. Thus, the spleen was analysed to determine whether EXOs affect immune processes. Of note, it was found that EXOs could diffuse into the spleen after 2 days and continue to accumulate at day 10 (Fig. 5A and B). EXOs were also observed in CD68-positive macrophages in spleen tissues (Fig. 5C).

Additionally, NK cells can limit tumourigenesis in the absence of functioning T-lymphocytes $(40,41)$. Therefore, 
A

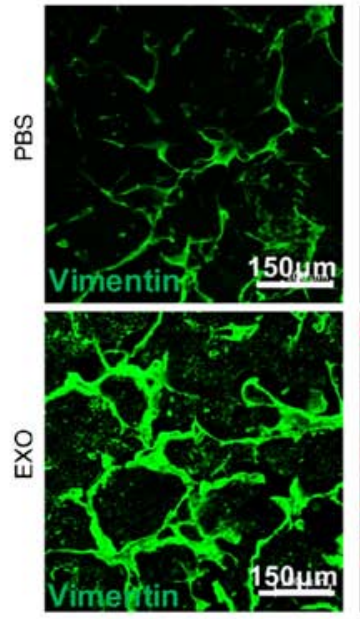

(Tumour)

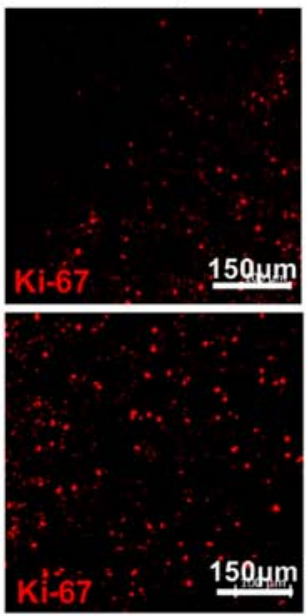

$50 \mu m$
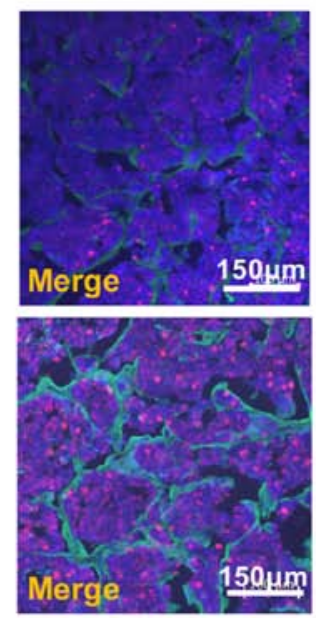

D

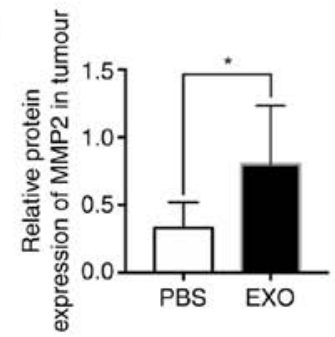

B
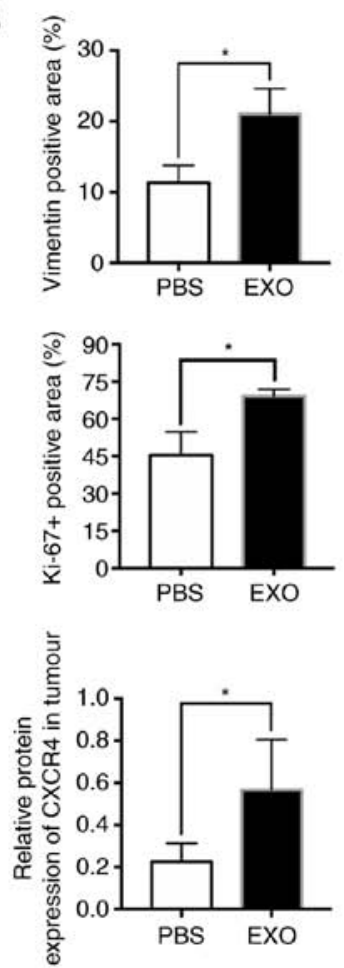

E
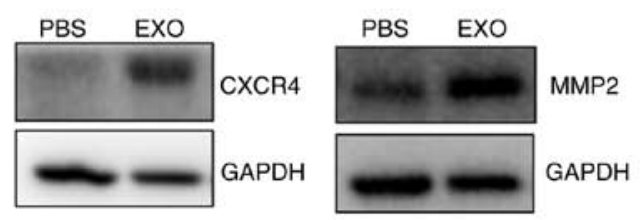

MMP2

GAPDH
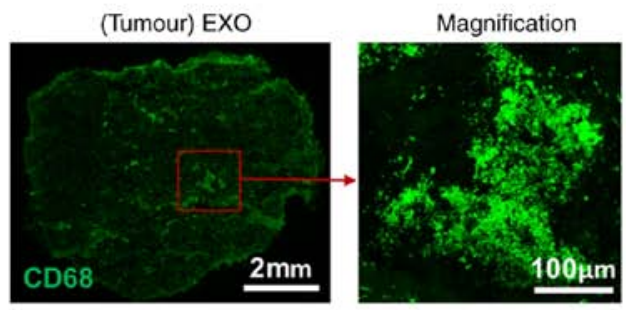

$\mathrm{F}$

G
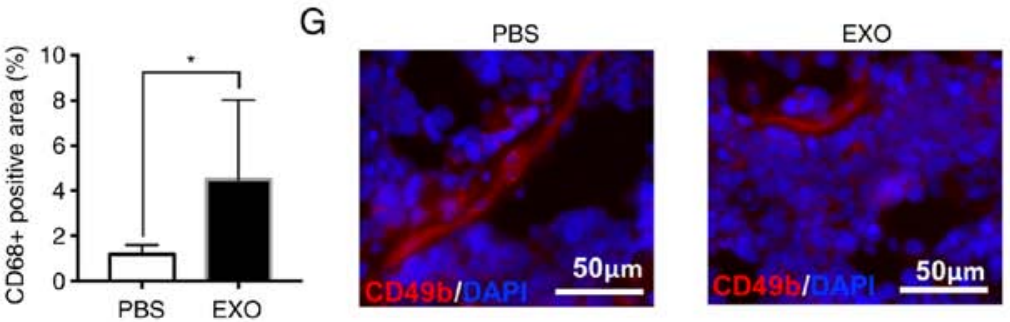

$\mathrm{H}$

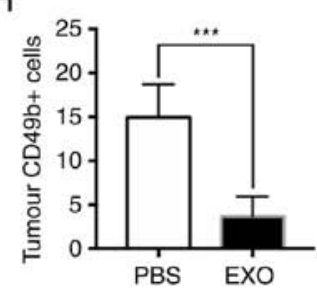

Figure 4. EXOs derived from WERI-Rb1 cells could promote the malignancy of retinoblastoma. (A) Vimentin (green) and Ki-67 (red) were labelled by immunofluorescence. Scale bar, $150 \mu \mathrm{m}$. (B) Quantitative data showing the relative positive area of Vimentin and Ki-67 in tumours (n=5). (C) Western blotting showed CXCR4 and MMP2 protein expression in tumours from the PBS-injected and EXO-injected groups. (D) Semi-quantification of CXCR4 and MMP2 expression in tumours (n=5). (E) Staining of CD68 (green) in PBS-injected and EXO-injected tumours. Scale bar, 2 mm or $100 \mu$ m. (F) Quantitative data showed that CD68-positive cells were increased by EXO injection $(\mathrm{n}=6)$. (G) Staining of CD49b (red) in PBS-injected and EXO-injected tumours. Scale bar, $50 \mu \mathrm{m}$. (H) Quantitative data showed that CD49b-positive cells were decreased $(\mathrm{n}=5)$. ${ }^{*} \mathrm{P}<0.05$ and ${ }^{* * *} \mathrm{P}<0.001$. EXO, exosome; CXCR4, C-X-C chemokine receptor type 4.

spleen tissues were double stained with antibodies against Ki-67 and CD45 to determine the number and proliferative activity of leukocytes (Fig. 5D). CD45-positive leukocytes, which include granulocytes, monocytes and lymphocytes, control the innate immune response (42). The present data showed that EXOs significantly decreased the number of leukocytes in the spleen (PBS, 109.30 \pm 52.11 ; EXO, 37.54 \pm 21.42 ; ${ }^{*} \mathrm{P}<0.05$; Fig. 5E). More specifically, EXOs also significantly decreased the ratio of cells co-expressing Ki-67 and CD45 (white triangle), which indicated that compared with the control, EXOs inhibited leukocyte prolif-

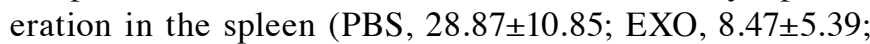
${ }^{* *} \mathrm{P}<0.01$; Fig. 5F). Similarly, immunofluorescence staining of CD49b, a pan-marker of NK cells (43), indicated that NK cells were significantly decreased in the spleens of the EXO-injected groups compared with the sham operation and PBS-injected groups (sham, 41.28 \pm 6.24 ; PBS, 37.81 \pm 18.08 ;

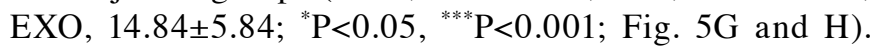
Collectively, these data demonstrated that EXOs inhibited the innate immune response in vivo. 
A (Spleen)

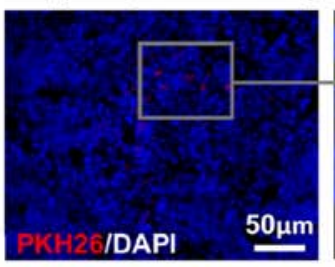

C

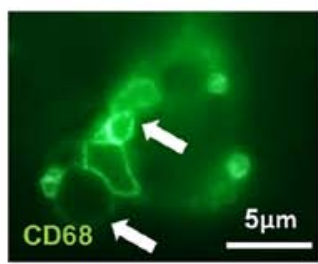

B
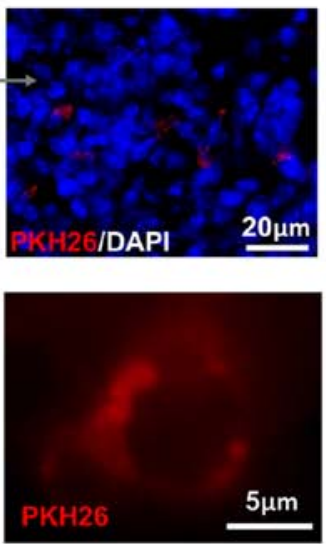
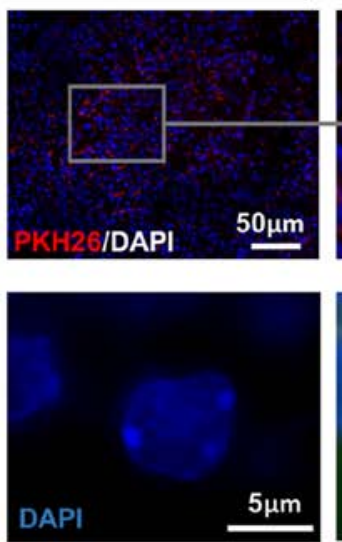

Day 10
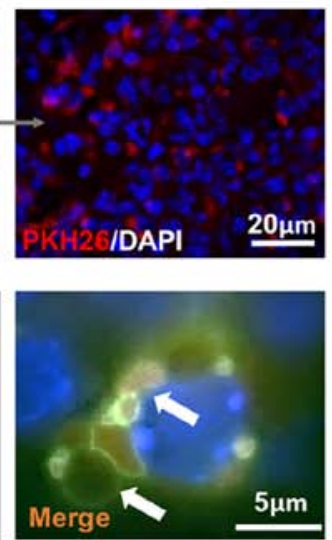

D

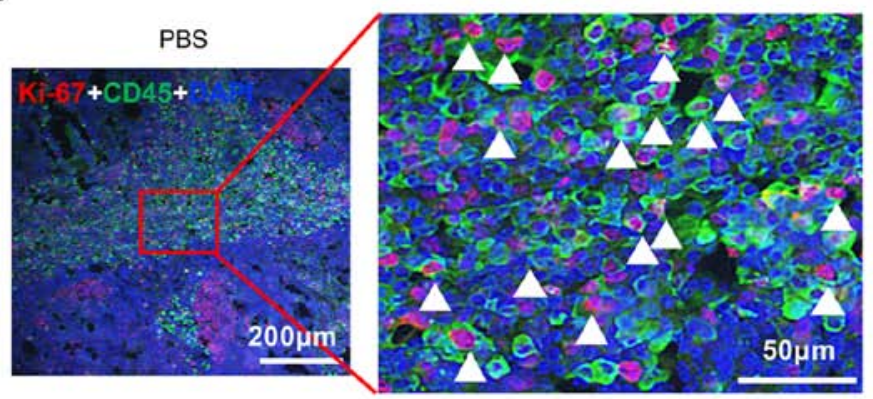

E
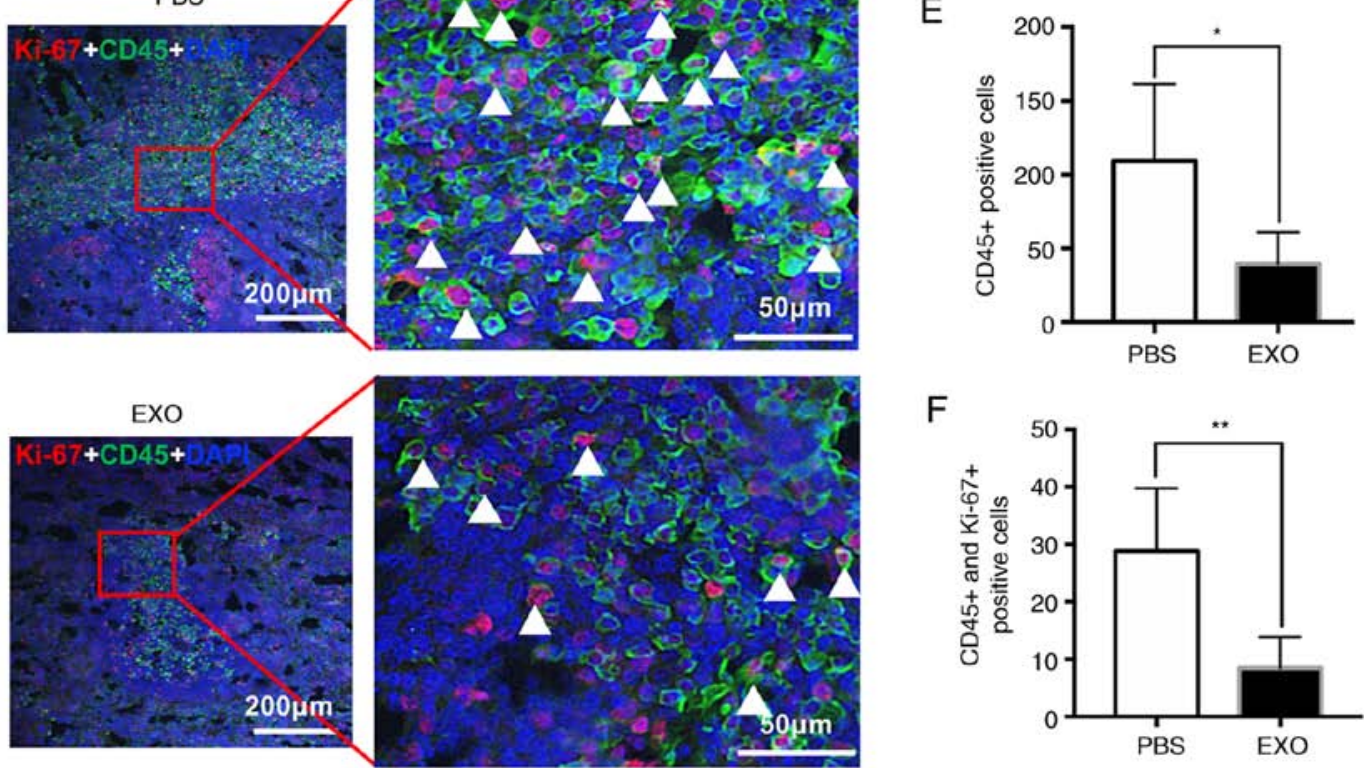

$\mathrm{F}$

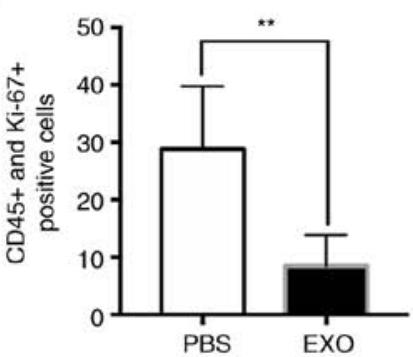

G

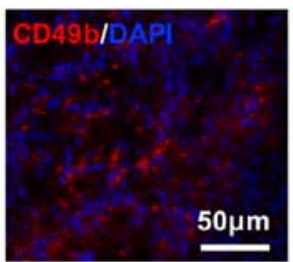

Sham

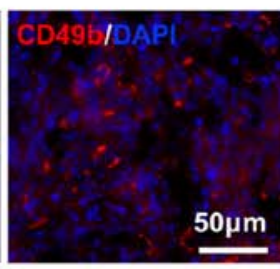

PBS

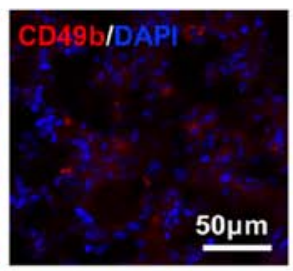

EXO
$\mathrm{H}$

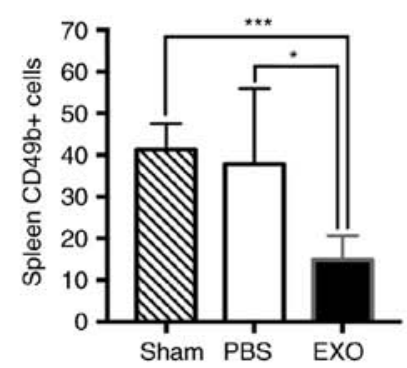

Figure 5. EXOs derived from WERI-Rb1 cells inhibit innate immunity in vivo. PKH26 EXOs (red) were internalized by cells from spleen tissues (A) 2 or (B) 10 days following EXO injection. Scale bar, 50 or $20 \mu \mathrm{m}$. (C) EXOs labelled by PKH26 were engulfed by CD68-positive macrophages in the spleen (green, CD68; red, PKH26; blue, DAPI). Scale bar, $5 \mu \mathrm{m}$. (D) Ki-67 (red) and CD45 (green) were labelled by immunofluorescence in spleens from the PBS-injected or EXO-injection groups. Scale bar, 200 or $50 \mu \mathrm{m}$. (E) Quantification data showed CD45-positive cells in spleens from the PBS-injected and EXO-injected groups ( $\mathrm{n}=5$ ). (F) Quantification of CD45 and Ki-67 double-positive cells in spleens from the PBS-injected and EXO-injected groups $(\mathrm{n}=5)$ ). $(\mathrm{G})$ Staining of CD49b (red) in spleens from the Sham (normal mice), PBS-injected and EXO-injected groups. Scale bar, $50 \mu \mathrm{m}$. (H) Quantification of CD49b-positive cells in spleens from the Sham $(n=3)$, PBS-injected $(n=5)$ and EXO-injected groups $(n=5) .{ }^{*} \mathrm{P}<0.05,{ }^{* *} \mathrm{P}<0.01$ and ${ }^{* * * *} \mathrm{P}<0.001$. EXO, exosome.

EXOs derived from WERI-Rb1 cells accelerate retinoblastoma metastasis. To explore the effects of EXOs on retinoblastoma metastasis, the liver, which was the closest organ to the subcutaneous tumour, was analysed. As shown in Fig. 6A, EXOs were observed in the cells around the liver sinusoids 2 days following the EXO injection and only appeared in the cells near the liver sinusoids. At day 10, EXOs (red) appeared in distant liver tissues and were mainly engulfed by Kupffer cells (CD68-positive), demonstrating that EXOs could spread throughout liver tissues and accumulate in macrophages (white arrows; Fig. 6B). Additionally, macroscopic images of liver metastatic nodules shown in Fig. 6C indicated that EXO injection led to more metastatic lesions (white arrowheads, metastatic liver nodules). Three livers from the EXO-injection 
A

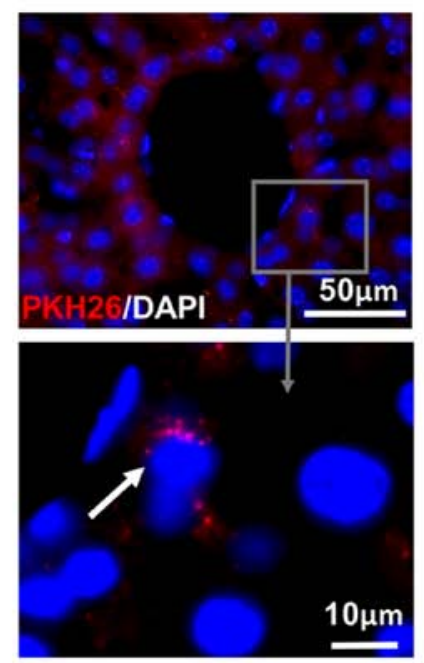

B
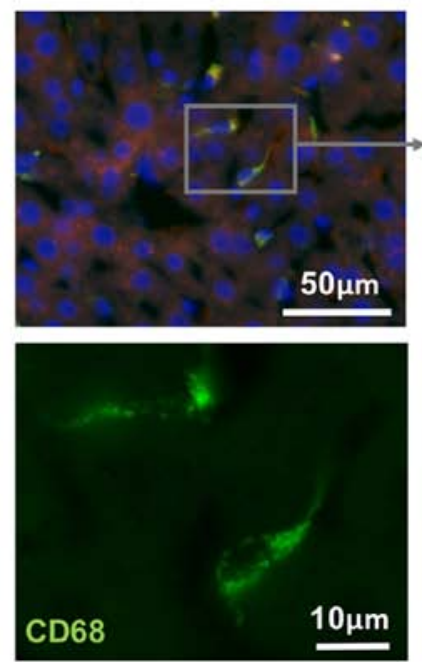

Day 10
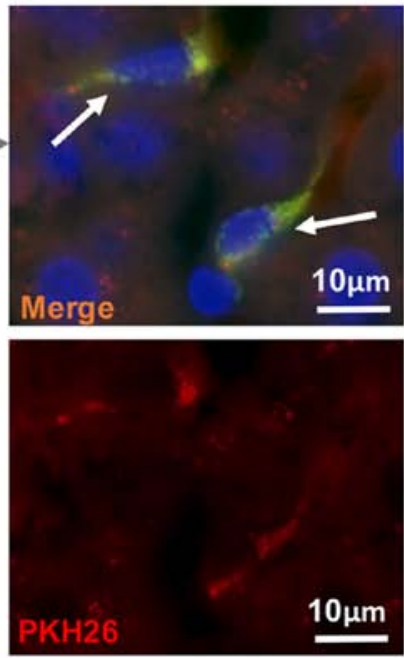

C
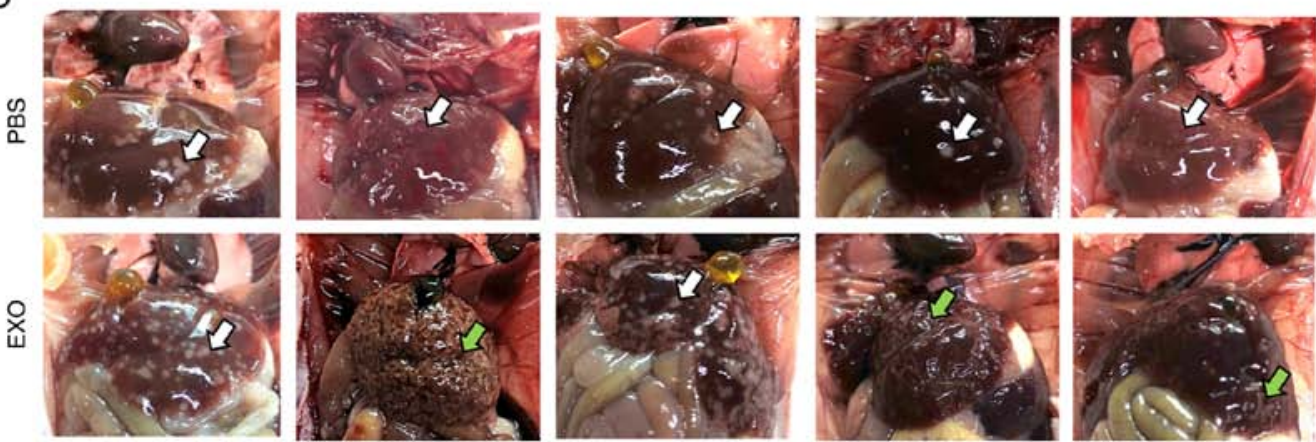

D
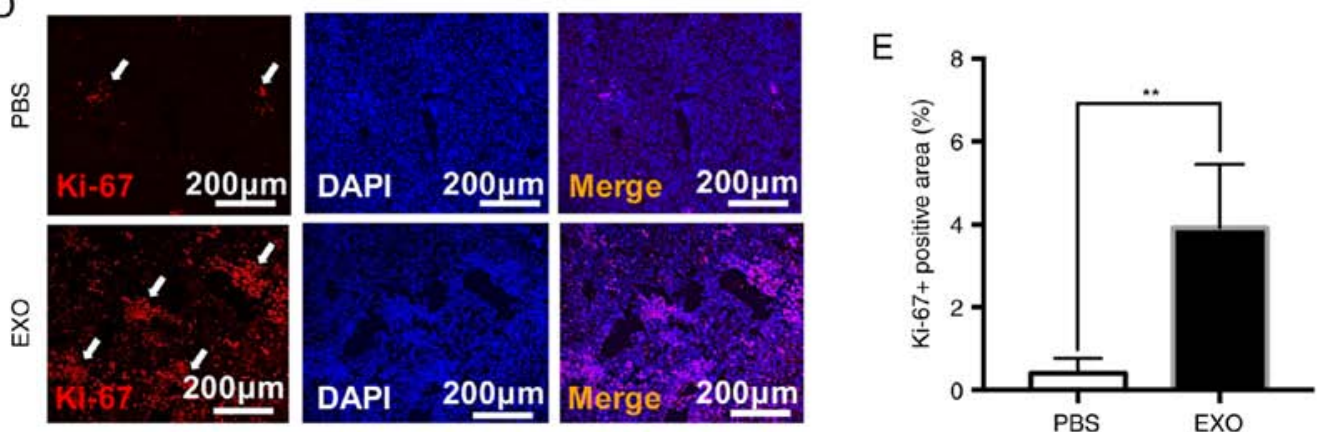

Figure 6. EXOs derived from WERI-Rb1 cells accelerate retinoblastoma metastasis. PKH26-labelled EXOs (red) were internalized by CD68-positive Kupffer cells (green) from liver tissues (A) 2 or (B) 10 days following EXO injection. DAPI was used to stain nuclei, and CD68 (green) was used to label macrophages. Scale bar, 50 or $10 \mu \mathrm{m}$. (C) Macroscopic appearance of livers from the PBS-injected and EXO-injected group (white arrowhead, metastatic liver nodules; green arrowheads, liver cirrhosis). (D) Staining of Ki-67 (red) in livers from the PBS-injected and EXO-injected groups. Scale bar, $200 \mu \mathrm{m}$. (E) Quantitative data showed that the Ki-67-positive area (\%) was increased by EXO injection $(\mathrm{n}=5) .{ }^{* *} \mathrm{P}<0.01$. EXO, exosome.

group were cirrhotic, which indicated liver deterioration (green arrowheads, liver cirrhosis). Then, the excised livers were stained with $\mathrm{Ki}-67$. It was found that livers from the EXO-injected group exhibited increased Ki-67-positive areas, which was consistent with metastatic nodules in the liver tissues (white arrowheads; PBS, 0.405 $\pm 0.353 \%$; EXO, $3.926 \pm 1.533 \%$; ${ }^{* *} \mathrm{P}<0.01$; Fig. $6 \mathrm{D}$ and E). Thus, EXOs derived from WERI-Rb1 cells may exhibit a promoting effect on tumour metastasis.

Constitution of EXOs derived from WERI-Rb1 cells. Since EXOs derived from WERI-Rb1 cells significantly affected tumour malignancy, innate immunity and metastasis as aforementioned, the expression of a selection of miRNAs and proteins involved in tumour deterioration in EXOs were analysed via RT-qPCR and western blotting. As shown in Fig. 7A, miR-92a, miR-20a, miR-129 and miR-17 were detected. Moreover, the chemokine receptor CXCR4 was not only expressed in WERI-Rb1 cells but was also detected in EXOs (Fig. 7B). TSP-1, a matricellular protein, plays multiple roles in tumour development and was not observed in WERI-Rb1 cells, which was consistent with our previous study (44). However, of note, TSP-1 was detected in EXOs. CXCR4 and TSP-1 are involved in proliferation and TAM recruitment (45-51). Thus, the contents of EXOs may play a key role in EXO-mediated tumour progression. 


\begin{tabular}{cccc} 
A miRNA & Detection & miRNA & Detection \\
\hline hsa-miR-17 & + & hsa-miR-126a & - \\
hsa-miR-18a & - & hsa-miR-129 & + \\
hsa-miR-19a & - & hsa-miR-135b & - \\
hsa-miR-19b & - & hsa-miR-136 & - \\
hsa-miR-20a & + & hsa-miR-155 & - \\
hsa-miR-92a & + & hsa-miR-223 & - \\
hsa-miR-125a & - & hsa-miR-451a & - \\
\hline
\end{tabular}

B
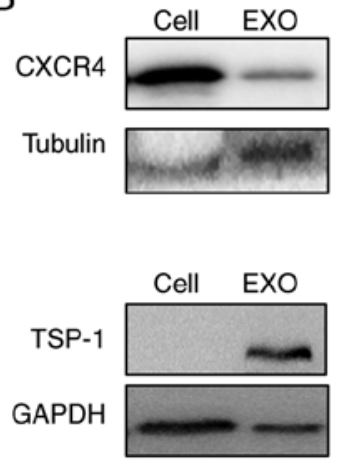

Figure 7. Constitution of EXOs derived from WERI-Rb1 cells. (A) Reverse transcription-quantitative PCR analysis of a selection of the miRNAs related to tumour deterioration in EXOs derived from WERI-Rb1 cells. (B) Western blot images showing CXCR4 and TSP-1 protein expression in WERI-Rb1 cells and EXOs derived from WERI-Rb1 cells. EXO, exosome; CXCR4, C-X-C chemokine receptor type 4; TSP-1, thrombospondin-1; miR/miRNA, microRNA; + , positive expression; -, negative expression.

\section{Discussion}

A growing body of evidence has suggested that EXOs play an important role in tumour invasion and metastasis $(13,14,52)$. EXOs derived from retinoblastoma cells may have multiple effects on retinoblastoma development. In the present study, it was found that EXOs could inhibit the antitumour effects of macrophages and induce BMSCs to promote tumour growth. In vivo, through a xenotransplantation model in nude mice, the data showed that EXOs significantly increased tumour growth. Remarkably, EXOs injected around the tumour infiltrated the tumour tissue, spleen and liver. The changes in TAMs, leukocytes and NK cells induced antitumour activity that was inhibited by EXO infiltration of these tissues. Analysis of the contents of EXOs showed that EXOs were rich in miRNAs and proteins involved in tumour deterioration. Thus, these data provided direct evidence, both in vitro and in vivo, to support the notion that EXOs derived from retinoblastoma promote tumour progression by infiltrating the microenvironment.

Notably, the present study showed that EXOs derived from WERI-Rb1 cells slightly increased the growth of those cells in vitro (Fig. 1F), but had a more significant effect in vivo (Fig. 3C). After incubation with EXOs, WERI-Rb1 cell viability was slightly increased. The expression levels of PCNA, a specific cell proliferation marker, were the same in cells treated with EXOs compared with the control (Fig. 1G). However, EXOs extracted from WERI-Rb1 cells significantly enhanced PCNA protein levels and inhibited tumour apoptosis in vivo (Fig. 3E and F). The ratio of Ki-67-positive cells following EXO treatment was significantly higher than that after control treatment (Fig. 4B). Tumour growth in the EXO-injected group was increased $\sim 4.0$-fold 10 days after treatment (Fig. 3B and C). Therefore, the inconsistency between tumour proliferative activity in vitro and in vivo indicated that EXOs promote tumour growth by affecting the peripheral microenvironment.

Indeed, it was found that the viability of macrophages was significantly inhibited by EXOs in vitro. The inflammatory cytokines IL- 6 and MCP-1 were increased in macrophages incubated with EXOs (Fig. 2). Both IL-6 and MCP-1 could further contribute to tumour growth and metastasis (6). Similarly, IL-6 and MCP-1 levels were also increased in BMSCs, leading to elevated WERI-Rb1 cell viability. Moreover, EXOs could exacerbate the microenvironment in xenograft tumours. EXOs infiltrated and accumulated in the tumour, spleen and liver. TAMs were enhanced and NK cells were decreased in tumours injected with exosomes (Fig. 4). Similarly, PKH26-labelled EXOs were directly taken up by macrophages in the spleen. CD45-positive leukocytes and NK cells, a type of lymphocyte that predominantly mediates innate antitumour immunity, were significantly decreased in spleens with EXO treatment (Fig. 5). Moreover, EXOs appeared in distant liver tissues and were mainly engulfed by Kupffer cells (Fig. 6B). In accordance with the roles of TAMs, leukocytes and NK cells, EXOs derived from WERI-Rb1 cells accelerated the proliferation, malignancy and metastasis of retinoblastoma in vivo. Therefore, the present findings indicated that EXOs modify the tumour microenvironment and promote tumour progression (Fig. 8).

The contents of EXOs include small non-coding RNA molecules, such as miRNAs, piwi-interacting RNAs, tRNA-derived small RNAs, and a series of proteins (53). It was found that miRNAs (miR-92a, miR-20a, miR-129 and miR-17), CXCR4 and TSP-1 were detectable in EXOs derived from retinoblastoma cells. According to previous studies, miRNAs (miR-92a, miR-20a, miR-129 and miR-17), CXCR4 and TSP-1 are involved in TAM recruitment and proliferation (45-51). For example, miR-92a stimulates the secretion of the proinflammatory cytokine IL-6 in TAMs, which in turn promotes tumour cell proliferation, invasion and metastasis by interacting with the surrounding microenvironment (46). CXCR4 accelerates TAM recruitment $(36,48)$. However, the role of TSP-1 expression in tumorigenesis is complex and controversial. Some studies have reported that TSP-1 could inhibit tumour angiogenesis and suppress tumour growth in various types of cancer, such as cervical cancer, lung cancer 


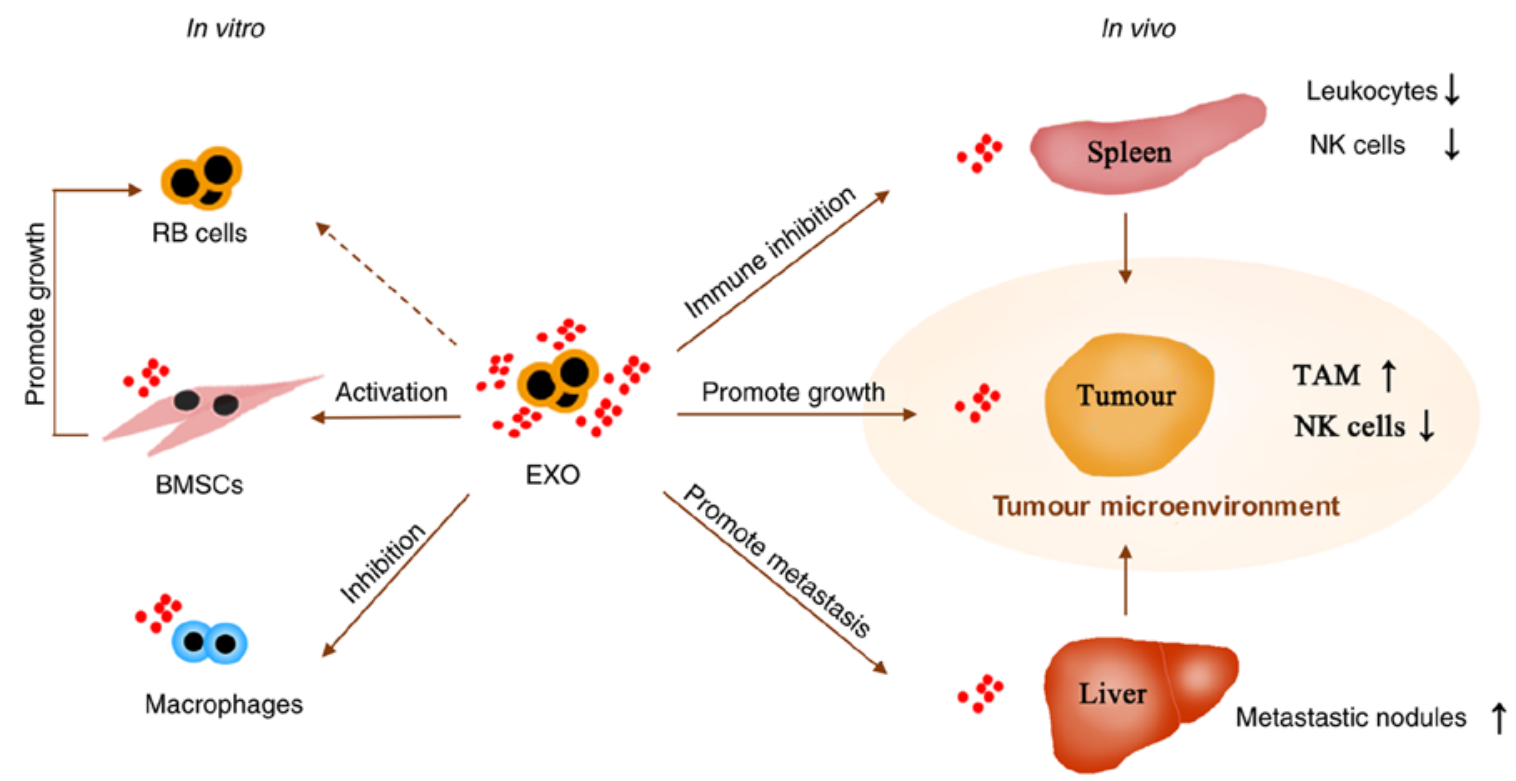

Figure 8. Roles of EXOs derived from WERI-Rb1 cells in retinoblastoma. In vitro, EXOs derived from RB cells could promote cell growth via activation of BMSCs and inhibit the antitumour effect of macrophages. In vivo, EXOs derived from RB cells could promote tumour growth, inhibit immune cells in the spleen and promote liver metastasis. EXO, exosome; RB, retinoblastoma; BMSC, bone marrow mesenchymal stem cells; NK, natural killer; TAM, tumour-associated macrophages.

and melanoma $(54,55)$. Other studies have suggested that TSP-1 can be detected in multiple types of cancers, including prostate cancer, breast cancer and cutaneous melanoma, and is associated with tumour proliferation, migration and metastasis, leading to a poor prognosis (56-59). Specifically, Xiao et al (49) reported that EXO-transferred TSP-1 can activate TAMs and promote malignant migration in oral squamous cell carcinoma, which is consistent with the present results. Based on the aforementioned previous studies, the function of elevated TSP1 expression in retinoblastoma EXOs may promote retinoblastoma progression. However, a limitation of the present study was that only a select few miRNAs and proteins were investigated. The overall identification of protein and miRNA profiles of EXOs will be performed in future studies.

Overall, the present study elucidated the role and function of EXOs derived from retinoblastoma cells in retinoblastoma growth and metastasis. The findings of this study suggested that retinoblastoma EXOs may be a therapeutic target that can be exploited to inhibit retinoblastoma by regulating its composition; alternatively, inhibitors that interfere with EXO uptake could be developed. Thus, the present study warrants future clinical exploration of the suppression of retinoblastoma with EXOs in the paediatric population.

\section{Acknowledgements}

Not applicable.

\section{Funding}

The present study was supported by grants from the National Natural Science Foundation of China (grant no. 81670848) and the Science and Technology Planning Project of Guangzhou City (grant no. 201803010091).

\section{Availability of data and materials}

The datasets used and/or analysed during the current study are available from the corresponding author upon reasonable request.

\section{Authors' contributions}

SC and XC designed and performed the study, analysed the data and drafted the manuscript. JQ, PC, XH and YW assisted in performing the experiments and analysed the data. JieZ, MY, CW, NW and YY participated in collecting data and organizing the figures. JG was involved in designing the study and provided professional advice. SC and JinZ reviewed the manuscript and organized the figures. KY and JinZ designed the study, analysed the data, administered the project and supervised the manuscript. All authors have read and approved the final manuscript.

\section{Ethics approval and consent to participate}

All animal experiments adhered strictly to the ARVO Statement for the Use of Animals in Ophthalmic and Vision Research and were approved and monitored by the Institutional Animal Care and Use Committee of the Zhongshan Ophthalmic Center [approval no. SYXK (YUE) 2018-101, 2018-168, 2019-009].

\section{Patient consent for publication}

Not applicable.

\section{Competing interests}

The authors declare that they have no competing interests. 


\section{References}

1. Jain M, Rojanaporn D, Chawla B, Sundar G, Gopal L and Khetan V: Retinoblastoma in Asia. Eye (Lond) 33: 87-96, 2019.

2. Francis JH, Roosipu N, Levin AM, Brodie SE, Dunkel IJ Gobin YP and Abramson DH: Current treatment of bilateral retinoblastoma: The impact of intraarterial and intravitreous chemotherapy. Neoplasia 20: 757-763, 2018.

3. Abramson DH, Shields CL, Munier FL and Chantada GL: Treatment of retinoblastoma in 2015: Agreement and disagreement. JAMA Ophthalmol 133:1341-1347, 2015.

4. Xu L, Li W, Shi Q, Wang M, Li H, Yang X and Zhang J: MicroRNA-936 inhibits the malignant phenotype of retinoblastoma by directly targeting HDAC9 and deactivating the PI3K/AKT pathway. Oncol Rep 43: 635-645, 2020.

5. Quail DF and Joyce JA: Microenvironmental regulation of tumor progression and metastasis. Nat Med 19: 1423-1437, 2013.

6. Kitamura T, Qian BZ and Pollard JW: Immune cell promotion of metastasis. Nat Rev Immunol 15: 73-86, 2015.

7. Sica A and Mantovani A: Macrophage plasticity and polarization: In vivo veritas. J Clin Invest 122: 787-795, 2012.

8. Kim J and Bae JS: Tumor-associated macrophages and neutrophils in tumor microenvironment. Mediators Inflamm 2016: 6058147, 2016.

9. Saunderson SC, Dunn AC, Crocker PR and McLellan AD CD169 mediates the capture of exosomes in spleen and lymph node. Blood 123: 208-216, 2014.

10. DeNardo DG, Brennan DJ, Rexhepaj E, Ruffell B, Shiao SL, Madden SF, Gallagher WM, Wadhwani N, Keil SD, Junaid SA, et al: Leukocyte complexity predicts breast cancer survival and functionally regulates response to chemotherapy. Cancer Discov 1: 54-67, 2011.

11. Théry C, Zitvogel L and Amigorena S: Exosomes: Composition, biogenesis and function. Nat Rev Immunol 2: 569-579, 2002

12. Mathieu M, Martin-Jaular L, Lavieu G and Théry C: Specificities of secretion and uptake of exosomes and other extracellular vesicles for cell-to-cell communication. Nat Cell Biol 21: 9-17, 2019.

13. Peinado H, Alečković M, Lavotshkin S, Matei I, Costa-Silva B, Moreno-Bueno G, Hergueta-Redondo M, Williams C, García-Santos G, Ghajar CM, et al: Melanoma exosomes educate bone marrow progenitor cells toward a pro-metastatic phenotype through MET. Nat Med 18: 883-891, 2012.

14. Maji S, Chaudhary P, Akopova I, Nguyen PM, Hare RJ, Gryczynski I and Vishwanatha JK: Exosomal annexin II promotes angiogenesis and breast cancer metastasis. Mol Cancer Res 15: 93-105, 2017.

15. Messenger SW, Woo SS, Sun Z and Martin TFJ: A $\mathrm{Ca} 2+$-stimulated exosome release pathway in cancer cells is regulated by Munc13-4. J Cell Biol 217: 2877-2890, 2018.

16. Haga H, Yan IK, Takahashi K, Wood J, Zubair A and Patel T: Tumour cell-derived extracellular vesicles interact with mesenchymal stem cells to modulate the microenvironment and enhance cholangiocarcinoma growth. J Extracell Vesicles 4: 24900, 2015.

17. Boyiadzis $\mathbf{M}$ and Whiteside TL: The emerging roles of tumor-derived exosomes in hematological malignancies. Leukemia 31: 1259-1268, 2017.

18. Feng Q, Zhang C, Lum D, Druso JE, Blank B, Wilson KF, Welm A, Antonyak MA and Cerione RA: A class of extracellular vesicles from breast cancer cells activates VEGF receptors and tumour angiogenesis. Nat Commun 8: 14450, 2017.

19. Klingeborn M, Dismuke WM, Rickman CB and Stamer WD: Roles of exosomes in the normal and diseased eye. Prog Retin Eye Res 59: 158-177, 2017.

20. Soleimani M and Nadri S: A protocol for isolation and culture of mesenchymal stem cells from mouse bone marrow. Nat Protoc 4 102-106, 2009.

21. Théry C, Clayton A, Amigorena S and Raposo G: Isolation and characterization of exosomes from cell culture supernatants and biological fluids. Curr Protoc Cell Biol: Chapter 3: Unit 3.22, 2006.

22. Tian Y, Ma L, Gong M, Su G, Zhu S, Zhang W, Wang S, Li Z, Chen C, Li L, et al: Protein Profiling and Sizing of Extracellular Vesicles from Colorectal Cancer Patients via Flow Cytometry. ACS Nano 12: 671-680, 2018.

23. Friedrich R, Block S, Alizadehheidari M, Heider S, Fritzsche J, Esbjörner EK, Westerlund $\mathrm{F}$ and Bally $\mathrm{M}$ : A nano flow cytometer for single lipid vesicle analysis. Lab on a Chip 17: 830-841, 2017
24. Hoshino A, Costa-Silva B, Shen T, Rodrigues G, Hashimoto A, Mark MT, Molina H, Kohsaka S, Giannatale AD, Ceder S, et al: Tumour exosome integrins determine organotropic metastasis. Nature 527: 329-335, 2015.

25. Livak KJ and Schmittgen TD: Analysis of relative gene expression data using real-time quantitative PCR and the 2(-Delta Delta C(T)) method. Methods 25: 402-408, 2001.

26. Paschos GK, Ibrahim S, Song WL, Kunieda T, Grant G, Reyes TM, Bradfield CA, Vaughan CH, Eiden M, Masoodi M, et al: Obesity in mice with adipocyte-specific deletion of clock component Arntl. Nat Med 18: 1768-1777, 2012.

27. Connor KM, Krah NM, Dennison RJ, Aderman CM, Chen J, Guerin KI, Sapieha P, Stahl A, Willett KL and Smith LE: Quantification of oxygen-induced retinopathy in the mouse: A model of vessel loss, vessel regrowth and pathological angiogenesis. Nat Protoc 4: 1565-1573, 2009.

28. Balkwill F: The significance of cancer cell expression of the chemokine receptor CXCR4. Seminars in cancer biology. Semin Cancer Biol 14: 171-179, 2004.

29. Cao Y, Guangqi E, Wang E, Pal K, Dutta SK, Bar-Sagi D and Mukhopadhyay D: VEGF exerts an angiogenesis-independent function in cancer cells to promote their malignant progression. Cancer Res 72: 3912-3918, 2012.

30. Ortega J, Li JY, Lee S, Tong D, Gu L and Li GM: Phosphorylation of PCNA by EGFR inhibits mismatch repair and promotes misincorporation during DNA synthesis. Proc Natl Acad Sci USA 112: 5667-5672, 2015.

31. Zhao N, Tsuda H, Murofushi T, Imai K, Ochiai K, Yang P and Suzuki N: Chaetocin inhibits RANKL-induced osteoclast differentiation through reduction of Blimp1 in Raw264.7 cells. Life Sci 143: 1-7, 2015.

32. Ara T, Song L, Shimada H, Keshelava N, Russell HV, Metelitsa LS, Groshen SG, Seeger RC and DeClerck YA: Interleukin-6 in the bone marrow microenvironment promotes the growth and survival of neuroblastoma cells. Cancer Res 69: 329-337, 2009.

33. Tang Z, Li D, Hou S and Zhu X: The cancer exosomes: Clinical implications, applications and challenges. Int J Cancer 146: 2946-2959, 2020

34. Yerushalmi R, Woods R, Ravdin PM, Hayes MM and Gelmon KA: Ki67 in breast cancer: Prognostic and predictive potential. Lancet Oncol 11: 174-183, 2010.

35. Pastushenko I, Brisebarre A, Sifrim A, Fioramonti M, Revenco T, Boumahdi S, Keymeulen AV, Brown D, Moers V, Lemaire S, et al: Identification of the tumour transition states occurring during EMT. Nature 556: 463-468, 2018.

36. Chen Z, Pan X, Georgakilas AG, Chen P, Hu H, Yang Y, Tian S, Xia L, Zhang J, Cai X, et al: Tetramethylpyrazine (TMP) protects cerebral neurocytes and inhibits glioma by down regulating chemokine receptor CXCR4 expression. Cancer Lett 336: 281-289, 2013

37. Chen Q, Zhang JJ, Ge WL, Chen L, Yuan H, Meng LD, Huang XM, Shen P, Miao Y and Jiang KR: YY1 inhibits the migration and invasion of pancreatic ductal adenocarcinoma by downregulating the FER/STAT3/MMP2 signaling pathway. Cancer Lett 463: 37-49, 2019.

38. Takase N, Koma Y, Urakawa N, Nishio M, Arai N, Akiyama H, Shigeoka M, Kakeji Y and Yokozaki H: NCAM-and FGF-2-mediated FGFR1 signaling in the tumor microenvironment of esophageal cancer regulates the survival and migration of tumor-associated macrophages and cancer cells. Cancer Lett 380: 47-58, 2016.

39. Esbona K, Yi Y, Saha S, Yu M, Doorn RV, Conklin MW, Graham DS, Wisinski KB, Ponik SM, Eliceiri KW, et al: The presence of cyclooxygenase 2 , tumor-associated macrophages, and collagen alignment as prognostic markers for invasive breast carcinoma patients. Am J Pathol 188: 559-573, 2018.

40. Shultz LD, Lyons BL, Burzenski LM, Gott B, Chen X, Chaleff S, Kotb M, Gillies SD, King M, Mangada J, et al: Human lymphoid and myeloid cell development in NOD/LtSz-scid IL2R gamma null mice engrafted with mobilized human hemopoietic stem cells. J Immunol174: 6477-6489, 2005.

41. Shultz LD, Goodwin N, Ishikawa F, Hosur V, Lyons BL and Greiner DL: Human cancer growth and therapy in NOD/SCID/IL2R $\gamma$ null (NSG) mice. Cold Spring Harbor Protocols 2014: 694, 2014

42. Bartal I, Melamed R, Greenfeld K, Atzil S, Glasner A, Domankevich V, Naor R, Beilin B, Yardeni IZ and Ben-Eliyahu S: Immune perturbations in patients along the perioperative period: Alterations in cell surface markers and leukocyte subtypes before and after surgery. Brain Behav Immun 24: 376-86, 2010. 
43. Arase H, Saito T, Phillips JH and Lanier LL: Cutting edge: The mouse NK cell-associated antigen recognized by DX5 moncoclonal antibody is CD49b ( $\alpha 2$ integrin, very late antigen-2). J Immunol 167: 1141-1144, 2001

44. Chen P, Yu N, Zhang Z, Zhang P, Yang Y, Wu N, Xu L, Zhang J, Ge J, Yu K, et al: Thrombospondin-1 might be a therapeutic target to suppress RB cells by regulating the DNA double-strand breaks repair. Oncotarget 7: 6105-6120, 2016.

45. Hirschberger S, Hinske LC and Kreth S: MiRNAs: Dynamic regulators of immune cell functions in inflammation and cancer. Cancer Lett 431: 11-21, 2018.

46. Casadei L, Calore F, Creighton CJ, Guescini M, Batte K, Iwenofu OH, Zewdu A, Braggio DA, Bill KL, Fadda P, et al: Exosome-derived miR-25-3p and miR-92a-3p stimulate liposarcoma progression. Cancer Res 77: 3846-3856, 2017.

47. Xu Z, Zhao L, Zhu LY, He M, Zheng L and Wu Y: MicroRNA-17, 20a regulates the proangiogenic function of tumor-associated macrophages via targeting hypoxia-inducible factor $2 \alpha$. PLoS One 8: e77890, 2013.

48. Kim DI, Kim E, Kim YA, Cho SW, Lim JA and Park YJ Macrophage densities correlated with CXC chemokine receptor 4 expression and related with poor survival in anaplastic thyroid cancer. Endocrinol Metab (Seoul) 31: 469-475, 2016.

49. Xiao M,Zhang J, Chen W and Chen W: M1-like tumor-associated macrophages activated by exosome-transferred THBS1 promote malignant migration in oral squamous cell carcinoma. J Exp Clin Cancer Res 37: 143, 2018.

50. Bonauer A, Carmona G, Iwasaki M, Mione M, Koyanagi M, Fischer A, Burchefield J, Fox H, Doebele C, Ohtani K, et al: MicroRNA-92a controls angiogenesis and functional recovery of ischemic tissues in mice. Science 324: 1710-1713, 2009.

51. Mathiyalagan P, Liang Y, Kim D, Misener S, Thorne T, Kamide CE, Klyachko E, Losordo DW, Hajjar RJ and Sahoo S: Angiogenic mechanisms of human $\mathrm{CD}_{3} 4^{+}$stem cell exosomes in the repair of ischemic hindlimb. Circ Res 120: 1466-1476, 2017.
52. Tkach $\mathrm{M}$ and Théry $\mathrm{C}$ : Communication by extracellular vesicles: Where we are and where we need to go. Cell 164: 1226-1232, 2016.

53. Huang X, Yuan T, Liang M, Du M, Xia S, Dittmar R, Wang D, See W, Costello BA, Quevedo F, et al: Exosomal miR-1290 and miR-375 as prognostic markers in castration-resistant prostate cancer. Eur Urol 67: 33-41, 2015.

54. Tsuchida R, Osawa T, Wang F, Nishii R, Das B, Tsuchida S, Muramatsu M, Takahashi $\mathrm{T}$, Inoue $\mathrm{T}$, Wada $\mathrm{Y}$, et al: BMP4/Thrombospondin-1 loop paracrinically inhibits tumor angiogenesis and suppresses the growth of solid tumors. Oncogene 33: 3803-3811, 2014.

55. Ramchandani D and Mittal V: Thrombospondin in tumor microenvironment. Adv Exp Med Biol 1272: 133-147, 2020

56. Firlej V, Mathieu JR, Gilbert C, Lemonnier L, Nakhlé J, Gallou-Kabani C, Guarmit B, Morin A, Prevarskaya N, Delongchamps NB, et al: Thrombospondin-1 triggers cell migration and development of advanced prostate tumors. Cancer Res 71: 7649-7658, 2011.

57. Horiguchi H, Yamagata S, Rong Qian Z, Kagawa S and Sakashita N: Thrombospondin-1 is highly expressed in desmoplastic components of invasive ductal carcinoma of the breast and associated with lymph node metastasis. J Med Invest 60: 91-96, 2013.

58. Borsotti P, Ghilardi C, Ostano P, Silini A, Dossi R, Pinessi D, FoglieniC,ScatoliniM,LacalPM,FerrariR,etal.Thrombospondin-1 is part of a Slug-independent motility and metastatic program in cutaneous melanoma, in association with VEGFR-1 and FGF-2. Pigment Cell Melanoma Res 28: 73-81, 2015.

59. Byrne GJ, Hayden KE, McDowell G, Lang H, Kirwan CC, Tetlow L, Kumar S and Bundred NJ: Angiogenic characteristics of circulating and tumoural thrombospondin-1 in breast cancer: Int J Oncol 31: 1127-1132, 2007.

This work is licensed under a Creative Commons Attribution-NonCommercial-NoDerivatives 4.0 International (CC BY-NC-ND 4.0) License. 